\title{
Strategic Design Towards Platform Collaboration in The Newspaper Industry: A Design Science Research Study
}

\author{
Erol Kazan \\ University of Jyväskylä \\ erol.it.kazan@jyu.fi
}

\author{
Hadi Ghanbari \\ University of Jyväskylä \\ hadi.ghanbari@jyu.fi
}

\author{
Tuure Tuunanen \\ University of Jyväskylä \\ tuure@tuunanen.fi
}

\author{
Mengcheng Li \\ University of Jyväskylä \\ mengcheng.m.li@student.jyu.fi \\ Sanja Tumbas \\ IESE Business School \\ stumbas@iese.edu
}

\begin{abstract}
The newspaper industry is challenged by unsustainable business models. To stabilize dwindling revenue streams, publishers opted for digital subscriptions as one avenue for generating additional revenue streams. Large publishers have indeed benefited from rising subscription numbers. However, smaller publishers are challenged to achieve the same results. Some of the root causes are high churn rates, adoption costs and lock-in effects of subscription services. News aggregator platforms may promise newspaper publishers a large pool of paying readers. But platform fees and the loss of direct customer relationships enact commercial barriers among publishers. This study proposes design science research to address the aforementioned shortcomings by designing a collaborative subscription service in a Nordic country. Building on strategic alliance, digital platform and business model literature, this research aims to identify pertinent design principles that create positive conditions for a collaborative subscription services in the newspaper industry.
\end{abstract}

\section{Introduction}

Technological advancements have transformed most content-based industries (e.g., video, music, text) into on-demand economies. One industry that witnessed major changes in its modus operandi is the newspaper industry. Mobile computing (e.g., smartphones) empowered readers to gain access to a variety of articles at their fingertips. Online channels by newspaper publishers continue to gain traction and generate complementary revenues besides traditional print channels. Moreover, publishers continue to make strategic investments into their online channels (e.g., creating digital business units, hiring chief digital officers) to achieve competitiveness and financial sustainability in the long run.
However, these changes were accompanied with challenges as well. The popularity of online adblockers continues to undermine the commercialization efforts of publishers. Another ongoing challenge is competition. Publishers compete against new and resourceful competitors such as global social media platforms (e.g., Facebook), or public broadcasters, where the latter offer journalistic content in a subsidized fashion. Clearly, these dynamics are not in favor of newspaper publishers. This is especially concerning for smaller ones, as they do not have the same resource base and market reach to offset their costs.

In recent years, though, an increasing number of publishers opted to replicate their traditional print business in the form of paywalls and digital subscriptions [1]. Yet, digital subscriptions have their own difficulties; First, after years of free content, publishers need to convince readers to pay for online content in the first place. Secondly, the churn rate, which is the cancelation of subscriptions, is still at a high rate. The abovementioned observations suggest that there is still a misalignment in the value proposition between publishers and customers to pay for online content. In other words, business models for online newspaper have room for improvement [2, $3]$.

Arguably, the misalignment in value propositions relates to the depth and breadth of online articles. Typically, each online newspaper serves specific market segments with targeted content (e.g., regional or local newspapers). To access different types of articles (e.g., financial news, investigative journalism or tech reviews), readers would have to look for alternatives, which would require a second (or more) newspaper subscription. In these kinds of scenarios, the newspaper industry imposes readers high adoption costs, and hence, impacting the overall adoption of newspaper subscriptions. 
Meanwhile, technology organizations have recognized the potential to pool content by different providers into one service in the form of news aggregator platforms (Apple News + , Blendle). But publishers are hesitant to accept new powerful intermediaries, as they fear to be commoditized. Moreover, publishers are concerned to cannibalize their own revenue generating subscription services. In spite of that, publishers cannot ignore the prevailing trend of aggregated online news content. To illustrate, Apple generated 200,000 new subscribers for Apple News+ in the first two days [4]. In this kind of situations, where organizations face competitive challenges or resource constrains, management literature on competition suggests strategic alliances. Strategic alliances (e.g., industry consortia, joint ventures) are considered to be a way to create market entry barriers for prospective rivals, or outbalance organizational shortcomings (e.g., market reach, distribution channels) in a collaborative as well as competitive fashion $[5,6]$. So far, most publishers, however, had very few avenues for collaborations, and were rather mandatory in their nature and largely non-commercial (e.g., law on data protection). A strategic alliance among publishers in a commercial setup, like operating a collaborative and competitive subscription service is under researched area.

One solution to address the aforementioned challenges would be the development of a collaborative subscription service that takes the from an interorganizational digital platform [7, 8]. First, a subscription service that aggregates a pool of online newspapers would simplify the boarding process for new paying subscribers. Secondly, having access to a large pool of different online content would arguably increase the value proposition, and potentially reduce the churn rate of online newspaper subscriptions.

As this kind of service has its potential, we lack knowledge as to how to design a cooperative and competitive (i.e., coopetition) subscription service in the first place. First, a subscription service that is coowned by multiple competing publishers is different compared to existing centralized news aggregators (e.g., Apple News + , Blendle). Furthermore, technical and commercial aspects such as platform architecture and business models have to be aligned and orchestrated between competing publishers which offer the same service. In this sense, a collaborative subscription service for the online newspaper industry suggests a different set of understanding, and by that design principles regarding technology and business related features. Therefore, we propose following research question: What are the design principles of a collaborative subscription service for the online newspaper industry?

To answer the research question, we draw on strategic alliance, digital platform, business model literature, and apply design science methodology to derive design principles for prototypes that resembles a collaborative subscription service $[1,3,5]$. These interrelated research streams are deemed to be suitable to identify positive conditions for collaboration from a technical and business viewpoint, as well as develop test scenarios to evaluate the effectiveness of different design principles.

This study contributes to the aforementioned research streams, as well as presenting a fitting response to a call for more design science studies related to digital platforms [8]. From a practitioner viewpoint, this study could have major implications for a Nordic newspaper industry. A successful subscription service may strengthen the relationships between publishers and readers, and present a competitive alternative to centralized news aggregator platforms.

\section{Theoretical Background}

\section{Newspaper Studies}

Literature has studied the newspaper industry through various theoretical lenses. Scholars tried to understand the merger dynamics among newspapers and the resulting economic implications (e.g., price of newspapers) [9], how open innovation unfolds in the Danish and Swedish newspaper industries [10, 11], how dynamic capabilities are leveraged during industry transformations [12], understanding newspapers as multi-sided platforms [13], or how online publishers become more entrepreneurial by innovating with new content delivery and business models $[14,15]$.

Overall, existing newspaper studies provide valuable insights about publishers embedded in different theoretical environments. Yet, we have a paucity of studies as to how to deliberately design a coopetitive newspaper platforms to address conjoint commercialization challenges. The recent competition dynamics by global platforms organizations (e.g., Apple News + ), or the rise of news aggregators platforms (e.g., Blendle) suggests to rethink the current status of the newspaper industry, how publishers compete and how online 
content is monetized. One way to achieve competitiveness is to increase the collaboration among publishers.

\section{Strategic Alliances}

Today's firm competition is increasingly driven by strategic networks or alliances, where multiple organizations pool their capabilities and resources to co-create valued product and services. In the strategic management literature, these types of organizational arrangements are synonymous with coopetition or strategic alliances $[5,16]$, where direct competitors pool carefully selected resources and capabilities to achieve mutual economic benefits. Strategic alliances are difficult to replicate as they are outcomes of complex managerial processes [5]. In the same vein, the ability to enter or forge strategic alliance is unevenly distributed. For instance, the value of certain resources or capabilities might be perceived to be interchangeable, which weakens the bargaining position of an alliance seeker [5]. The motivation for organizations to team-up with other organizations, who are in most cases direct competitors, is to build sustainable competitive advantages. Considering competitiveness in digital industries (e.g., social media), digital organizations are considered to be competitive, if they possess high market reach, or have the ability to attract partners to co-create innovations within a business network [17]. In the same way, if digital organizations are not sufficiently equipped for competition, literature suggest strategic alliances as a mean to compensate their organizational shortcomings. Accordingly, firms lacking industry-specific resources (e.g., market reach) may join strategic alliances to compensate for their deficiencies, or create preemptive market entry barriers [5]. As more business environments follow the logic of platform markets, strategic alliances can be understood as interorganizational digital platforms.

\section{Digital Platforms}

Digital platforms are business network promoting technology architectures [7]. Within business networks, digital platforms orchestrate services and technology components to foster innovation with various platform stakeholders. Scholars studied many facets of digital platforms, such as operating systems [18, 19], app stores [20], music distribution [21, 22] e-commerce [23], enterprise resource planning systems [24-26], game consoles [27], or mobile payment platforms [28]. A common theme among these studies is governance and control. Like in strategic alliances, digital platforms are constantly confronted balancing with the needs of existing and new stakeholders to maintain attractiveness and competitiveness, while avoiding fragmentation that would deteriorate the overall service quality [19].

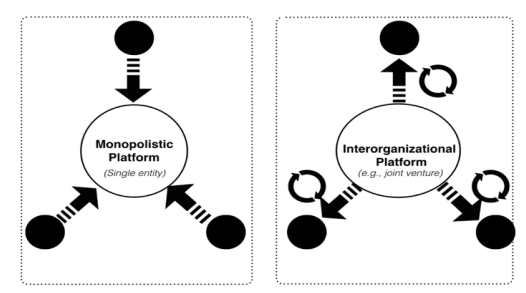

Figure 1. Two Types of Digital Platforms

Interorganizational digital platforms, which are basically technological manifestations of strategic alliances, orchestrate resources to co-create valued products and services (e.g., content). As this types of digital platform have clearly their advantages, stakeholders of interorganizational digital platforms face challenges such as reduced control over technology architectures, increased coordination costs, or technology incompatibilities that may cause ripple effects in slowing down the overall platform performance [29]. Accordingly, if the costs of belonging to an interorganizational platform outweigh the benefits, platform stakeholders might be inclined to reduce their involvement, hence reducing effectiveness (e.g., market reach), or exit the platform all together to achieve flexibility. Hence, becoming more monopolistic in their platform profiles (cf. Figure 1), which grants control over how a service creates and captures business value. In other words, regaining complete control over their business model.

\section{Digital Business Models}

The business model research stream has received considerable attention among scholars in their bid to explain the logic of how organizations create and capture value [2, 3, 30-33]. In the digital domain, digital business models can be understood through four generic elements: 1) value proposition (e.g., product or service offer), (2) value capture (e.g., pricing), (3) value architecture (e.g., platform), and lastly (4) value network (e.g., strategic alliance).

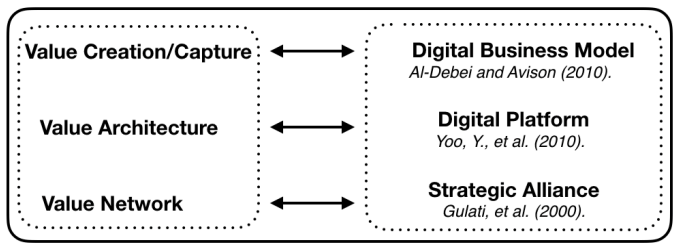

Figure 2. Design Analytical Lens 
In the newspaper industry context, business models studies have explored how credibility impacts a publisher's monetization strategies [34], the benefits of mobile apps to decrease the churn rate [35], the conversation rates of freemium business models [36], studies exploring relationship between free and paid news articles [1, 37], or generic open business models in the Danish newspaper industry [38].

Without doubt, the aforementioned newspaper studies provide valuable insights from different theoretical perspectives. However, we lack understanding as to how to design digital business models in a collaborative fashion. As previously illustrated, digital business models require the alignment of value propositions, value capture, value architecture and value network [3] to be effective. Accordingly, we deem strategic alliances, digital platforms and digital business models as suitable theoretical foundations, and analytical lenses (see Figure 2) to enquire and derive design principles for a collaborative subscription service for the newspaper industry.

\section{Methodology}

Our research design needs to reflect close involvement with the practice and delivery of a particular solution.

Hence, we follow a design science research methodology (DSRM) that is well developed and has a decades old tradition in Information Systems research. DSRM [39] builds on these DSR process models and suggests a way to conduct design science research in information systems. It is comprised of six phases: (1) identify the problem and motivation; (2) define the objectives; (3) design; (4) demonstrate; (5) evaluate; and (6) communicate [39].

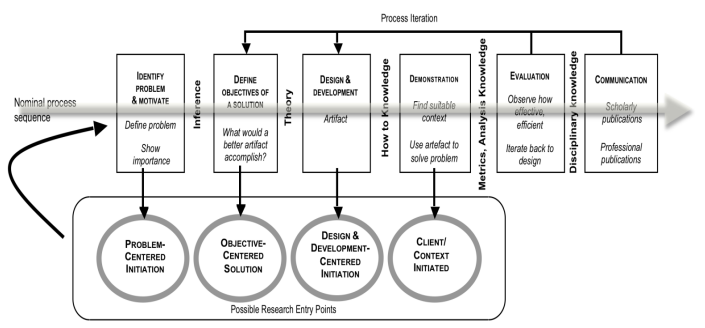

Figure 3. DSR Methodology, Adapted from [39]

The DSRM starts with the identification of research problem(s) and the motivation for the research (see Figure 3). Based on evidence, reasoning, and inference, the process continues towards defining the objectives of a solution to solve the research problem. This process should be based upon prior knowledge or literature in the given field of research. This knowledge is then used to design and develop an artefact and to create "how-to" knowledge.

Following that, an artefact is used to solve the predescribed problem. Thus, it is demonstrated in a suitable context before evaluating its effectiveness and/or efficiency. This approach leads to disciplinary knowledge, which is then communicated to both academia and practice. The process is iterative in its nature. In the next section, we report the design and development phases of the proposed collaborative subscription service artifact and its demonstration and preliminary evaluation.

\section{Design and Development}

To begin with, four semi-structured interviews have been conducted to gain preliminary insights from three different newspaper publishers and one industry association (i.e., 2x Chief Digital Officers, Chief Content Officer and Director New Growth) to identify barriers and common grounds for a collaborative newspaper subscription service [40]. The interviewed publishers consider the proposed solutions interesting while exhibiting skepticism. Most interviewees conveyed the notion to consider the proposed service rather complementary to their own services that does not result into cannibalizations effects. During a face-to-face interview, a research team member probed a chief digital officer regarding the feasibility of the proposed service. She states: "We haven't seen it to make it profitable, if you figure it out [...] we are open to it. But for now, we want to build our revenue model [on] our own subscription model and [for] our own customers. In regards to the business model, the chief digital officer emphasizes that: "it has to give us revenues [...], [and] doesn't eat our customer base".

To initiate development, the research team studied existing newspaper subscription services to understand their generic onboarding processes (e.g., account registration, payment method) and their mechanisms in accessing news articles on desktop computers (i.e., web-based). Besides newspapers, the research team expanded their studies on other marketplaces and news aggregators (e.g., Blendle, Apple AppStore) to understand their onboarding processes, pricing, and especially the way how content can be discovered. In the same vein, we aimed to translate the discovery mechanisms for the purpose of this study (see Figure 3).

To demonstrate the user experience in different scenarios (e.g., topping up user accounts, accessing paywalled content, wallet functionalities), interactive 
wireframes were developed. Based on the gathered insights and several discussion rounds inside the research team, the proposed subscription service has been conceptualized by divided them into two different, but interrelated prototypes (i.e., front and back prototypes) with the following functionalities:

Front-End Prototype. The first prototype is a webbased interface through which users can register and access a pool of online articles based on different topics, popularity or newness. As such, users pay for their service with different payment methods to access content until the end of their subscription period. Alternatively, the service supports micropayments for accessing paywalled online content without a digital subscription. The end user facing prototype allows us test different pricing structures to evaluate the performance of different business models.

Back-End Prototype. The second prototype presents a database to track and record user purchases, spending and access to different newspaper articles. In so doing, the proposed system needs a cookie management system to track browser activities. In this sense, the browser serves as a connector between publisher's websites and the proposed subscription service. At the end of the month, the content providers' monthly balance will be calculated based on various parameters (e.g., attention, time, read lines, visits) and generated revenues.

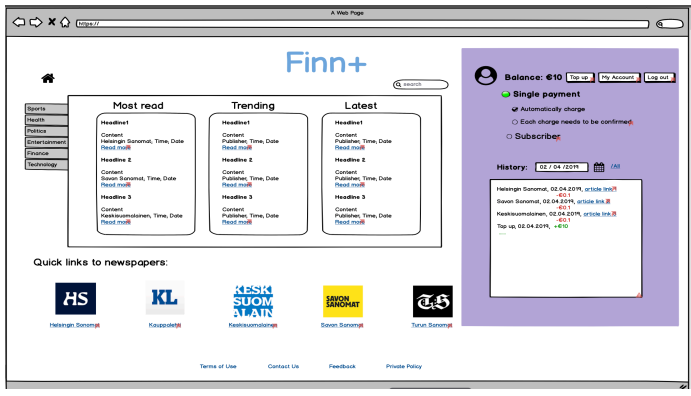

Figure 3. Prototype Concept

\section{Proof-of-Concept Evaluation}

In DSRM [39], the evaluation of the proposed artefacts (e.g., collaborative subscription service) are divided into two sub-activities: demonstration and evaluation. In the demonstration phase, the proposed artefact/proof-of-concept (e.g., wireframes) is demonstrated to pertinent stakeholders (e.g., publishers) to convey its anticipated utility and generalizable value proposition. In other words, the proposed artefact might work to solve a problem within a specific context (e.g., newspaper industry) [41]. In regards to the evaluation phase, the artefact is subject to a formalized process to assess its performance (e.g., increased usage) [39]. Compared to quantitative assessment methods, where an artefact's performance is quantified, qualitative assessment occurs largely in an intersubjective fashion, through means such as observation, feedback, group discussions, or interpretations [42]. A qualitative assessment approach is considered to be particularly useful to assess abstract and tacit organizational aspects (i.e., strategy, business related tensions, business model) [43].

After several design iterations, as well as considering the insights from the first interviews rounds, the research team conducted a workshop with a group of representatives from leading Nordic newspaper publishers (e.g., chief digital officers, business development mangers) and members from the media industry association to demonstrate the artefact and to elicit feedback to obtain further insights. At the beginning of workshop, the research team has demonstrated the proposed solution to workshop participants to convey the basic idea and functionality of the proposed service to achieve a common understanding. During the workshop, we elicited feedback and opinions related to technical and business aspects that are pertinent to micropayments and collaborative subscription service.

\section{Technical Aspects}

In regards to the technical feasibility of the proposed collaborative subscription service, workshop participants unanimously concluded that there are no particular challenges from a technical viewpoint. As stated by a Chief Digital Officer (i.e., CDO): "Pretty much everything is technically feasible, if you put enough resources, there is nothing there that couldn't be done [...] it will obviously demand some work on the subscription management solution side".

To determine the ideal metric to measure active reading that could serve as a proxy for revenue sharing, a CDO states: "just thinking off top of my mind, I would say certain percentage of the length of the article. Let's say it was 2000 characters and read at least 1200 [...] that is a fairly usable metric, since the length of the content varies greatly".

In the case of micropayments: "I don't see [problems] from a technical point of view [...] of course, it would be a lot of work". Referring to the user experience for micropayments: "it shouldn't make the purchase flow harder, at least the same or easier [...] if it gets 1\% harder than the amount of money that we lose is quite significant" Another 
participant suggests: "optimally it would be like Amazon's one-click solution". In regards to refunds, it was suggested that "every micropayment provider limits the refunds per month, maybe one or two per month".

\section{Business Aspects}

On micropayments: It is much more easier business wise, if someone goes to publisher A's property reads and pays for it, publisher A gets the money [minus] a service fee, that is very straightforward. However, another publisher representative conveyed his concerns: "We have being doing some research in the area of micropayments, but always it's still tricky to find the business [...] If you sell single [articles] or day passes versus [monthly] subscriptions the math is completely different, [...], we measure every subscription by net present value and it is so much higher [compared] to individual articles. My Excel [doesn't] give me green light for micropayments, at least yet".

In regards to the collaborative subscription service, workshop participants were prompted with the question what would be ideal revenue share resulting into mixed results. One workshop participant suggests: "Generally thinking of a reasonable commission level, I would say maximum [...] 10\%, probably even less. The commission rates on mobile payments [...] is currently $7 \%$ or $8 \%$ with the telcos". Another publisher representative questioned the entire concept: "maybe this is not the correct question, the correct question would be if this going to increase the total market? [...] Personally, I think we get more money by selling [our own] subscriptions per brand. In elaborating it further: "Apple offers a global service that will increase market size for the publishers. But in the [Nordic country] case, we don't have the same effect, because we can only sell to [Nordic country] people. [...] it's not going to scale our business".

The overall sentiment among workshop participants is that the Nordic country market is already saturated and that such kinds of systems would be in direct competition to their existing subscription services. Nevertheless, the workshop participants may have discovered an avenue for the proposed solution in the form of an add-on subscriptions service that builds on existing newspaper subscriptions controlled by the publishers.

A business development manager alluded: "If you are a [Publisher B] subscriber and you can then on top of that buy this [i.e., add-on subscription], let's say 5 Euros per month than the risks are not that big for us." A CDO provided additional remarks: "I think [your] comment is pretty much straight forward, close to the fact how do you package your offering [...] there might be an incremental revenue source". A representative from a smaller newspaper shared same notion that there are potential synergy effects that an add-on subscription service could be limited to a certain number of articles: "for smaller publishers like us, it would be good. I think we are already reaching the audience [who are willing] to pay for the full service".

In questioning the workshop participants further, how to design the business model for the add-on subscription service, the CDO provided the example "you pay 5 Euros and you get 10 tokens per month and a premium article costs 3 tokens, regular 2 and the basic one 1 [to access articles] that you like to have. In elaborating it further: "tokens [are] one way to represent real money, it doesn't have to be necessarily tokens, it can 50 cents, 1 Euro, 1.99 Euro". In addition to that, the CDO emphasized: "But then there is the discovery problem. How do you really find the interesting pieces of content [...] that would demand some kind of aggregation and categorization".

\section{Discussion}

This study is motivated by a growing urgency to improve our understanding of how to design a collaborative subscription service ex-ante for the newspaper industry. The newspaper industry is still facing transformative challenges, and one area of challenge is a sustainable business model for online content. One solution that has gained traction in recent years are digital subscription services [1], promising newspaper publishers steady revenues. Subscription services, however, are characterized by high adoption costs and churn rates [17], where only large publishers have mainly benefited from this trend. One solution to overcome these challenges is a collaborative subscription service that embodies the features of an interorganizational digital platform, or in the management terminology known as strategic alliance [5]. Based on strategic alliance, digital platform and business model literature, we have conceptualized our design analytical lens (see Figure 2) to derive test and evaluation scenarios for our proposed prototype: a collaborative subscription service for a Nordic newspaper industry. The design principles are summarized in Table 1 in below. 
Table 1. Design Principles for Prototype

\begin{tabular}{|c|c|c|}
\hline Strategic Alliance & Digital Platform & Business Model \\
\hline Coopetition Alliance & Orchestrator Hub & Add-on Subscription \\
\hline Establish an alliance & Build an orchestrator & $\underline{\text { Service }}$ \\
\hline $\begin{array}{l}\text { that competes and } \\
\text { collaborates in a } \\
\text { hybrid business } \\
\text { network. }\end{array}$ & $\begin{array}{l}\text { hub that connects } \\
\text { publishers as loosely } \\
\text { coupled platform } \\
\text { proxies. }\end{array}$ & $\begin{array}{l}\text { Bundle limited add-on } \\
\text { subscription services } \\
\text { with unlimited } \\
\text { proprietary ones. }\end{array}$ \\
\hline
\end{tabular}

Strategic Alliance Design Principle. Research on strategic alliances suggests that organizations could achieve competitive advantages (e.g., market reach, innovation) by teaming up with their industry rivals. But joining or remaining in strategic alliances is a challenge as well, as resources and capabilities among alliance members are usually unevenly distributed or perceived to be tradeable, reducing incentives to establish alliances in the first place [5]. In regards to establishing new alliances, recent studies theorize that organizations who historically possessed dominance in their respective industries, exhibit organizational inertia, having difficulties in achieving agreements that could result into mutual benefits [44].

Findings from the interviews and workshop with newspaper representatives suggest there are indeed existing collaborations. However, their nature is rather non-commercial (e.g., data protection, standardizing account registrations etc.) echoing existing literature in some fashion [44]. Probing publishers' opinions regarding a shared subscription service (i.e., a commercial setup), workshop participants were not entirely convinced to fully support a collaborative subscription service. Publishers initially exhibited resistance against the demonstrated prototype, as it would replicate and compete directly with their own revenue generating subscription services.

Nevertheless, one option emerged during the workshop: publishers were open towards a hybrid business arrangement in form of an add-on subscription service. An add-on subscription service would be bundled with existing proprietary subscription services that are controlled by publishers. In this scenario, publishers would continue to compete in the market with their own subscriptions, while collaborating on an add-on version in a limited fashion. In other words, a strategic coopetition alliance that pools selected resources (i.e., articles) while competing with each other. Nonetheless, questions remained about the ownership and structure, the rules to join or exit the alliance, revenue share, or what kind of content shall be shared.
Design Principle for Strategic Alliances: A hybrid business network in the form of a coopetition alliance exhibits supportive conditions to create a collaborative subscription service.

Digital Platform Design Principle. Digital platforms are business network orchestrating information systems that consist of stable cores and interchangeable components to execute specific business strategies [45]. Prior literature on digital platforms have extensively studied how digital platform owners in various industry settings exercise governance and control to derive business value [7, 46]. These studies, though, were primarily focusing on digital platforms from a single owner perspective as their unit of analysis, and had rather ex post views to derive platform insights.

However, to understand design principles for collaborative and coopetitive digital platforms $e x-$ ante, it requires arguably a different set of understanding. The aforementioned strategic alliance design principle suggests a digital platform that is distributed in its profile, where publishers are reciprocally connected to a central hub at the peripheral. Accordingly, the proposed artefact that aggregates news articles by different publishers (i.e., content is still hosted on publisher's sites), would exhibit the profile of an orchestrator hub. An orchestrator hub would connect to different publisher systems and vice versa to form an interorganizational digital platform.

In this context, the publishers would continue to operate and control their own content and subscription services, and simultaneously act as a proxy at arm's length to the central hub (see Figure 1). In fact, these types of platforms are not uncommon, but challenging to establish as suggested by the strategic alliance literature [5]. For instance, in the payment industry, financial institutions cooperatively own mobile payment systems while competing for the same customers [29]. Nevertheless, questions remain regarding governance, technology incompatibilities, and the degree of shared components, subscription and user data.

Design Principle for Digital Platforms: An Orchestrator Hub that connects and manages publishers as loosely coupled platform proxies at arm's length exhibits supportive conditions to create a collaborative subscription service.

Business Model Design Principle. Business models are value creation and capture instantiations that describe how organizations generate revenues from 
their products and services [3]. Many of them are increasingly embedded in interdepended business networks (e.g., strategic alliances) to co-create value [47]. Prior research on business models for online content offered valuable insights such as subscription or usage fees [1]. The unit of analysis of these studies, however, is media organizations owned by single entities. As such, these types of studies explored organizations, which have monopolistic control about content creation, pricing and delivery.

In this study, however, we embrace a different unit of analysis, where a subscription service is operated by multiple organizations. Arguably, this kind of scenario suggests a different conceptualization for designing business models (e.g., platform fees, revenue share, pricing, or the number of accessible articles). The findings from the interviews and workshop suggest that publishers exhibit resistance to grant unlimited access to their content, as this would be in direct competition to their own subscription services. In other words, publishers would face the risk of cannibalization.

Insights gleaned from the workshop discussions suggest that publishers would rather prefer to limit the number of accessible articles for a collaborative subscription service, and bundle it with their own subscription (i.e., add-on). In this scenario, customers would have to purchase two different but complementary services. Questions remain regarding the number of accessible articles, the pricing of single articles (i.e., micropayment), the cost of the add-on subscription service, or the willingness of customers to pay for an additional subscription in the first place.

Design Principle for Business Model: An Add-on Subscription Service with limited numbers of accessible articles exhibits supportive conditions to create a collaborative subscription service.

This study aims to contribute to practice and research in various ways. First, the empirical context for our study is timely (i.e., newspaper industry), which is characterized by accelerated innovation and competition dynamics. Newspaper publishers are largely vertically integrated organizations that are alien to strategic alliances. Thus, this study presents a promising avenue for deriving new knowledge for the strategic alliance research stream. Secondly, this research aims to contribute to the design science literature by designing a problem-orientated solution in the form of an interorganizational digital platform [39], and thus, presents a fitting response to a call for more DSR studies in the digital platform context [8]. Lastly, our study aims to contribute to research by bridging knowledge gaps between the strategic alliance [5], digital platform [7], business model [3] literature. By studying their interrelatedness, we gain a better understanding and appreciation as to how to strategically design digital driven strategic alliances. From a practitioner viewpoint, this study could present a small, but concrete step towards establishing a collaborative subscription service for a Nordic newspaper industry, which would be a competitive alternative to centralized news aggregator platforms.

\section{Conclusion}

This study applies design science research to develop a problem-orientated solution for the newspaper industry. Based and strategic alliance, digital platform, and business model literature, this study has derived three generic design principles for developing a collaborative and coopetitive subscription service (i.e., prototype), which may generate additional revenue streams.

The derived design principles will be further utilized to evaluate proof-of-concepts and software protypes with leading media firms in a Nordic country. This study may exhibit limitations, as this research will be conducted in a Nordic newspaper industry context, as other countries may differ regarding regulations and specific market structures. Thus, exhibiting potentially limited applicability of our findings. Furthermore, we recognize that our study currently lacks a formal evaluation of the derived design principles. However, the formal evaluation phase of the study is already in progress.

To be specific, we currently are in the process of developing the software prototype to test the derived design principles. Subsequently, circa 200-250 consumer participants will be invited to test the software prototype later this year, which will assist us to collect data on their online news consumption behavior. Before prototype testing, we will conduct a pre-study survey to investigate participants' current news media consumption patterns and their volume. Ultimately, this will allow us to test different user scenarios, and the performances of different business models, which in turn will provide further insights about their impact on other derived design principles.

\section{References}

[1] H. Sjøvaag, "Introducing the Paywall," Journalism Practice, vol. 10, no. 3, 2016, pp. 304-322.

[2] J. Hedman and T. Kalling, "The business model concept: theoretical underpinnings 
and empirical illustrations," European Journal of Information Systems, vol. 12, no. 1, 2003, pp. 49-59.

[3] Al-Debei, M. M., \& Avison, D, "Developing a unified framework of the business model concept". European Journal of Information Systems, 19(3), 2010, 359-376.

[4] E. Lee., "Media Companies Take a Big Gamble on Apple". The New York Times, Retrieved from http://www.nytimes.com, 2019, 7th of June.

[5] R. Gulati, N. Nohria, and A. Zaheer, "Strategic networks," Strategic Management Journal, vol. 21, no. 3, 2000, pp. 203-215.

[6] R. Gulati, F. Wohlgezogen, and P. Zhelyazkov, "The two facets of collaboration: Cooperation and coordination in strategic alliances," The Academy of Management Annals, vol. 6, no. 1, 2012, pp. 531-583.

[7] Y. Yoo, O. Henfridsson, and K. Lyytinen, "Research commentary - The new organizing logic of digital innovation: An agenda for information systems research," Information Systems Research, vol. 21, no. 4, 2010, pp. 724-735.

[8] M. de Reuver, C. Sørensen, and R. C. Basole, "The digital platform: a research agenda," Journal of Information Technology, 2017, pp. 1-12.

[9] Chandra, A. \& Collard-Wexler, A., "Mergers in two-sided markets: An application to the Canadian newspaper industry", Journal of Economics \& Management Strategy, 18(4), 2009, 10451070.

[10] Thorén, C., Ågerfalk, P. J., \& Edenius, M., "Through the printing press: an account of open practices in the swedish newspaper industry", Journal of the Association for Information Systems, 15(11), 2014, 779-804.

[11] Holm, A. B., Günzel, F., \& Ulhøi, J. P, "Openness in innovation and business models: lessons from the newspaper industry", International Journal of Technology Management, 61(3/4), 2013, 324-348.

[12] Karimi, J., \& Walter, Z., "The role of dynamic capabilities in responding to digital disruption: A factor-based study of the newspaper industry. Journal of Management Information Systems, 32(1), 2015, 39-81.

[13] Evans, D. S., "The online advertising industry: Economics, evolution, and privacy.
Journal of Economic Perspectives, 23(3), 2009, 37-60.

[14] J. Karimi and Z. Walter, "Corporate Entrepreneurship, Disruptive Business Model Innovation Adoption, and its Performance: The Case of the Newspaper Industry," Long Range Planning, vol. 49, no. 3, 2016, pp. 342-360.

[15] Fetscherin, M., \& Knolmayer, G., "Business models for content delivery: An empirical analysis of the newspaper and magazine industry. International Journal on Media Management, 6(1-2), 2004, 4-11.

[16] W. Hoffmann, D. Lavie, J. J. Reuer, and A. Shipilov, "The interplay of competition and cooperation," Strategic Management Journal, vol. 39, no. 12, 2018, pp. 30333052.

[17] T. Eisenmann, G. Parker, and M. Van Alstyne, "Strategies For Two-Sided Markets," Harvard Business Review, Article vol. 84 , no. 10, 2006, pp. 92-101.

[18] Benlian, A., Hilkert, D., \& Hess, T., "How open is this Platform? The Meaning and Measurement of Platform Openness from the Complementers' Perspective" Journal of Information Technology, 30(3), 2015, 209228.

[19] J. West, "How open is open enough?: Melding proprietary and open source platform strategies," Research Policy, vol. 32, no. 7, 2003, pp. 1259-1285.

[20] Ghazawneh, A., \& Henfridsson, "A paradigmatic analysis of digital application marketplaces", Journal of Information Technology, 30(3), 2015, 198-208.

[21] R. A. Burgelman and A. S. Grove, "Crossboundary disruptors: powerful interindustry entrepreneurial change agents," Strategic Entrepreneurship Journal, vol. 1, no. 3-4, 2007, pp. 315-327.

[22] D. Tilson, C. Sorensen, and K. Lyytinen, "Platform Complexity: Lessons from the music industry," in the proceedings of the 46th Hawaii International Conference on System Sciences, IEEE, 2013, pp. 46254634.

[23] B. Tan, S. L. Pan, X. Lu, and L. Huang, "The Role of IS Capabilities in the Development of Multi-Sided Platforms: The Digital Ecosystem Strategy of Alibaba. com", Journal of the Association for Information Systems, vol. 16, no. 4, 2015, pp. 248-280. 
[24] M. Ceccagnoli, C. Forman, P. Huang, and D. J. Wu, "Cocreation of value in a platform ecosystem: the case of enterprise software," MIS Quarterly, vol. 36, no. 1, 2012, pp. 263290.

[25] S. Sarker, S. Sarker, A. Sahaym, and N. Bjørn-Andersen, "Exploring value cocreation in relationships between an ERP vendor and its partners: a revelatory case study," MIS Quarterly, vol. 36, no. 1, 2012, pp. 317-338.

[26] J. Wareham, P. B. Fox, and J. L. C. Giner, "Technology Ecosystem Governance," Organization Science, vol. 25, no. 4, 2014, pp. 1195-1215.

[27] C. Cennamo and J. Santalo, "Platform competition: Strategic trade-offs in platform markets," Strategic Management Journal, vol. 34, no. 11, 2013, pp. 1331-1350.

[28] Ondrus, J., Gannamaneni, A., \& Lyytinen, $\mathrm{K}$., "The impact of openness on the market potential of multi-sided platforms: a case study of mobile payment platforms", Journal of Information Technology, 30(3), 2015, 260-275.

[29] E. Kazan, C.-W. Tan, E. T. Lim, C. Sørensen, and J. Damsgaard, "Disentangling digital platform competition: The case of UK mobile payment platforms," Journal of Managenent Information Systems, vol. 35, no. 1, 2018, pp. 180-219.

[30] J. Magretta, "Why Business Models Matter," Harvard Business Review, Article vol. 80, no. 5, 2002, pp. 86-92.

[31] A. Osterwalder and Y. Pigneur, "Clarifying business models: Origins, present, and future of the concept," Communications of the Association for Information Systems, Article vol. 16, 2005, pp. 1-25.

[32] R. Amit and C. Zott, "Value creation in Ebusiness," Strategic Management Journal, vol. 22, no. 6-7, 2001, pp. 493-520.

[33] P. Timmers, "Business Models for Electronic Markets," Electronic Markets, vol. 8, no. 2, 1998, pp. 3-8.

[34] B. Berger, "Commerce-oriented revenue models for content providers: an experimental study of commerciality's effect on credibility," Electronic Markets, journal article vol. 28, no. 1, 2018, pp. 93-109.

[35] P. Winter and P. Alpar, "On the relationship between print and mobile channels for newspapers," Electronic Markets, vol. 28, no. 1, 2018, pp. 79-92.
[36] O. F. Koch and A. Benlian, "The effect of free sampling strategies on freemium conversion rates," Electronic Markets, journal article vol. 27, no. 1, 2017, pp. 6776.

[37] M. Fetscherin and G. Knolmayer, "Business Models for Content Delivery: An Empirical Analysis of the Newspaper and Magazine Industry," International Journal on Media Management, vol. 6, no. 1-2, 2004, pp. 4-11.

[38] A. B. Holm, F. Günzel, and J. P. Ulhøi, "Openness in innovation and business models: lessons from the newspaper industry," International Journal of Technology Management, vol. 61, no. 3/4, 2013, pp. 324-348.

[39] K. Peffers, T. Tuunanen, M. Rothenberger, and S. Chatterjee, "A Design Science Research Methodology for Information Systems Research," Journal of Management Information Systems, vol. 24, no. 3, 2007, pp. 45-77.

[40] R. K. Yin, Case study research: Design and methods. Sage, 2009.

[41] J. Venable, J. Pries-Heje, and R. Baskerville, "A comprehensive framework for evaluation in design science research," in the proceedings of the International Conference on Design Science Research in Information Systems, Springer, 2012, pp. 423-438.

[42] Tremblay, M. C., Hevner, A. R., \& Berndt, D. J., "Focus Groups for Artifact Refinement and Evaluation in Design Research" Communications of the Association for Information Systems, 26, 2010, pp-pp.

[43] R. Winter, "Design science research in Europe," European Journal of Information Systems, vol. 17, no. 5, 2008, pp. 470-475.

[44] P. Ozcan and F. M. Santos, "The market that never was: Turf wars and failed alliances in mobile payments, "Strategic Management Journal, vol. 36, no. 10, 2015, pp. 14861512.

[45] C. Y. Baldwin and K. B. Clark, Design rules: The power of modularity. MIT press, 2000.

[46] M. Pagani, "Digital business strategy and value creation: Framing the dynamic cycle of control points," MIS Quarterly, Article vol. 37, no. 2, 2013, pp. 617-632.

[47] C. K. Prahalad and V. Ramaswamy, "Cocreation experiences: The next practice in value creation," Journal of Interactive Marketing, vol. 18, no. 3, 2004, pp. 5-14. 